\title{
Intra-amniotic LPS modulates expression of antimicrobial peptides in the fetal sheep lung
}

\author{
Augusto F. Schmidt', Paranthaman S. Kannan', Matthew W. Kemp², Boris W. Kramer ${ }^{3}$, John P. Newnham², Alan H. Jobe' and \\ Suhas G. Kallapur'
}

BACKGROUND: Damage-associated molecular patterns (DAMPs) and antimicrobial peptides (AMPs) are components of pulmonary innate immunity and tissue repair. We hypothesized that DAMPs and AMPs would increase in response to fetal pulmonary inflammation caused by chorioamnionitis in a time-dependent manner.

METHODS: Fetal sheep were exposed to intra-amniotic saline or lipopolysaccharide (LPS) $(10 \mathrm{mg})$ between $5 \mathrm{~h}$ and $15 \mathrm{~d}$ prior to preterm delivery at $125 \pm 2 \mathrm{~d}$. Lung tissue mRNAs for proinflammatory cytokines; AMPs: myeloid AMP-29 (MAP29), dodecapeptide, sheep $\beta$-defensin-1 (SBD1), and sheep $\beta$-defensin-2 (SBD2); and DAMPs: interleukin (IL)-1a, lactoferrin, heat-shock protein-70 (HSP70), high-mobility group box protein-B1 (HMGB1), and receptor for advanced glycation endproducts (RAGE) were measured by reverse-transcriptase quantitative polymerase chain reaction. Immunohistochemistry of DAMPs and in situ hybridization of AMPs was performed.

RESULTS: IL-1 a, IL-1 $\beta, I L-6, I L-8, I L-10, M C P-1$, and tumor necrosis factor (TNF)-a mRNA increased after LPS exposure. MAP29, dodecapeptide, SBD1, and SBD2 mRNA were suppressed at 24h. MAP29 and dodecapeptide mRNA then increased at $8 \mathrm{~d}$. Lactoferrin increased at $24 \mathrm{~h}$. There were no changes for HMGB1, HSP70, or RAGE. MAP29 and dodecapeptide localized to alveolar cells, increased $8 \mathrm{~d}$ after exposure to LPS.

CONCLUSION: AMPs are initially suppressed in the fetal lung by LPS-induced chorioamnionitis. The late induction of MAP29 and dodecapeptide may be related to lung repair.

Chand horioamnionitis is a frequent cause of fetal inflammation and the lung is an important organ in initiating the fetal inflammatory response (1). Chorioamnionitis also has been inconsistently associated with bronchopulmonary dysplasia, with some studies reporting no association (2), while others report a positive association (3). A recent meta-analysis showed association of increased bronchopulmonary dysplasia with histological chorioamnionitis (4). However, in animal models of chorioamnionitis, the lung injury observed is mild and resolves despite continued exposure to proinflammatory mediators $(5,6)$, suggesting participation of repair mechanisms following the initial inflammatory insult.

In fetal lambs, intra-amniotic bacterial lipopolysaccharide (LPS) induces chorioamnionitis and lung inflammation (7). LPS signals the innate immune response by binding to the Toll-like receptor 4 (TLR4) and intra-amniotic LPS increases TLR4 mRNA expression and protein in the fetal lung $(8,9)$. The TLRs are part of a group of receptors called pattern recognition receptors, which recognize microorganisms through pathogenassociated molecular patterns, as well as noninfectious material and endogenous molecules released during cell injury called damage-associated molecular patterns (DAMPs) $(8,10)$.

DAMPs are constitutively present in the cytoplasm, nucleus, and granules of cells such as leukocytes and epithelial cells. They can activate both innate and adaptive immunity, being quickly released by degranulation or cell necrosis in response to infection or tissue injury, and can also be induced in response to cytokines (10). Several DAMPs have been identified, including highmobility group box-1 (HMGB1), heat-shock proteins (HSP), and lactoferrin. These DAMPs are able to recruit and activate inflammatory cells, including dendritic cells and are able to interact with both TLRs and interleukin (IL)-1 receptor. Even though not formally considered DAMPs, IL- $1 \alpha$ and lactoferrin have similar characteristics being constitutively expressed and trigger inflammatory responses upon release from necrotic cells (10).

Antimicrobial peptides (AMPs) are an essential part of the innate immune response. They not only have direct antimicrobial activity but are also involved in the modulation of inflammation and healing (11). Defensins and cathelicidins, the most extensively studied AMPs in mammals, are large cationic peptides with antimicrobial and immunomodulatory activity (12). In sheep, two $\beta$-defensins have been described: $\beta$-defensin- 1 (SBD1), and $\beta$-defensin 2 (SBD2) $(13,14)$. Several cathelicidins also have been described in sheep and the myeloid AMP 29 (MAP29) has been the most studied. The expression of defensins and cathelicidins are developmentally regulated with increased expression toward the end of gestation and with a subsequent postnatal decrease in different fetal tissues (13-15). However, their role in the fetal inflammatory response and

'Division of Pulmonary Biology, Cincinnati Children's Hospital Medical Center, University of Cincinnati, Cincinnati, Ohio; ${ }^{2}$ School of Women's and Infants' Health, The University of Western Australia, Perth, Australia; ${ }^{3}$ Department of Pediatrics, Maastricht University Medical Center, Maastricht, The Netherlands. Correspondence: Suhas G. Kallapur (suhas.kallapur@cchmc.org)

Received 22 November 2013; accepted 11 May 2014; advance online publication 10 September 2014. doi:10.1038/pr.2014.113 
tissue repair remains to be further elucidated. Therefore, we hypothesized that AMPs and DAMPs would increase with pulmonary inflammation from chorioamnionitis. We report

Table 1. Physiological variables of preterm lambs at birth

\begin{tabular}{llccc}
\hline Group & $n$ & Birth weight & Sex (M/F) & Cord blood $\mathrm{pH}$ \\
\hline Saline & 6 & $3.0 \pm 0.3$ & $3 / 3$ & $7.1 \pm 0.1$ \\
$5 \mathrm{~h}$ & 6 & $3.1 \pm 0.2$ & $2 / 4$ & $7.1 \pm 0.1$ \\
$12 \mathrm{~h}$ & 7 & $2.8 \pm 0.2$ & $5 / 2$ & $7.0 \pm 0.1$ \\
$24 \mathrm{~h}$ & 7 & $2.8 \pm 0.6$ & $4 / 3$ & $7.1 \pm 0.1$ \\
$2 \mathrm{~d}$ & 6 & $2.9 \pm 0.3$ & $3 / 3$ & $7.1 \pm 0.2$ \\
$4 \mathrm{~d}$ & 5 & $3.0 \pm 0.1$ & $2 / 3$ & $7.1 \pm 0.2$ \\
$8 \mathrm{~d}$ & 7 & $3.0 \pm 0.4$ & $2 / 5$ & $7.2 \pm 0.1$ \\
$15 \mathrm{~d}$ & 7 & $2.9 \pm 0.2$ & $3 / 4$ & $7.2 \pm 0.1$ \\
\hline
\end{tabular}

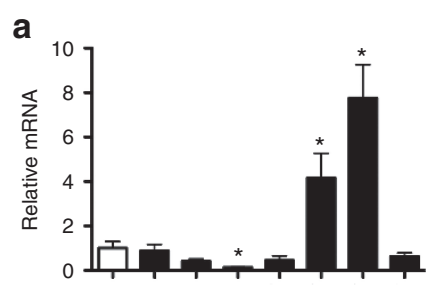

$\mathbf{b}_{15}$

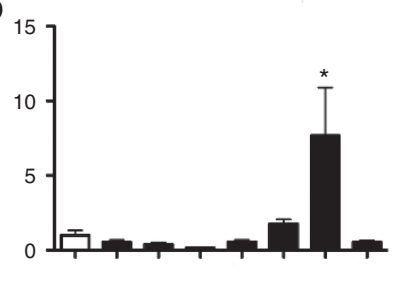

C

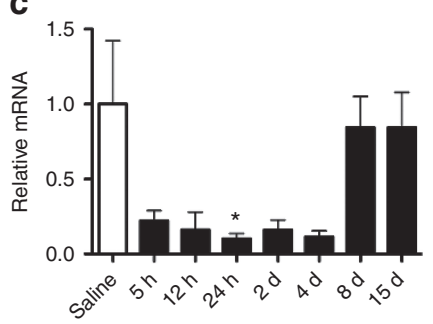

d

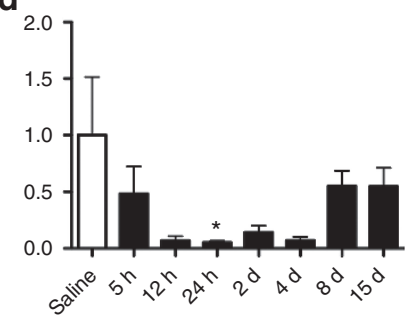

Figure 1. Time-dependent changes in the expression of antimicrobial peptides (AMPs) in preterm fetal sheep lung after intra-amniotic lipopolysaccharide (LPS) and mRNA expression of the antimicrobial peptides (a) myeloid AMPs (MAP)29, (b) dodecapeptide, (c) sheep $\beta$-defensin (SBD)1, and (d) SBD2 by reverse-transcriptase quantitative polymerase chain reaction using Taqman probes were analyzed. The AMP expression decreased at $24 \mathrm{~h}$ after LPS. The expression of MAP29 and dodecapetide increased at 4-8 d, whereas SBD1 and SBD2 returned to levels similar to controls. ${ }^{*} P<$ 0.05 compared to saline. novel information regarding the time course of expression of inflammatory cytokines and expression of DAMPs and AMPs in a clinically relevant preterm animal model.

\section{RESULTS}

\section{Animals}

All animals exposed to intra-amniotic LPS or saline were alive at delivery (Table 1). The $\mathrm{pH}$ values were low because the ewes were killed prior to the delivery of the fetuses, which resulted in high fetal $\mathrm{pCO}_{2}$ values. We previously reported decreased lymphocytes in the cord blood at 5,12 , and $24 \mathrm{~h}$ and increased neutrophils at $8 \mathrm{~d}$ for this series of animals (16).

\section{AMPs}

The mRNA levels of the $\beta$-defensins (SBD1 and SBD2) and cathelicidins (MAP29 and dodecapeptide) decreased $24 \mathrm{~h}$ after LPS exposure (Figure 1). However, the mRNA levels of the cathelicidins, had an eightfold increased expression at $8 \mathrm{~d}$. In contrast, the mRNA levels of SBD1 and SBD2 returned to levels similar to control by $8 \mathrm{~d}$.

\section{Localization of Cathelicidins mRNA}

In order to identify the location of the increased expression of cathelicidins at $8 \mathrm{~d}$, we performed in situ hybridization for cathelin-related peptide, which crossreacts with all the sheep cathelicidins. Lung sections from control lambs expressed cathelicidin mRNAs localized to the peripheral lung. The cell type appeared to be consistent with alveolar type II cells and occasional inflammatory cells. The number of positive cells and intensity of staining increased at $8 \mathrm{~d}$ after IA LPS exposure (Figure 2).

\section{Expression of DAMPs}

Expression of IL-1 $\alpha$ increased at $12 \mathrm{~h}$ after LPS (Figure 3 ). The mRNA for lactoferrin increased $24 \mathrm{~h}$ after exposure. There were no differences in the mRNA levels for HMGB1, receptor for advanced glycation endproducts (RAGE), or HSP70.

\section{Immunolocalization of DAMPs}

To characterize the expression of DAMPs in the lung, we performed immunohistochemistry for lactoferrin, HMGB1,

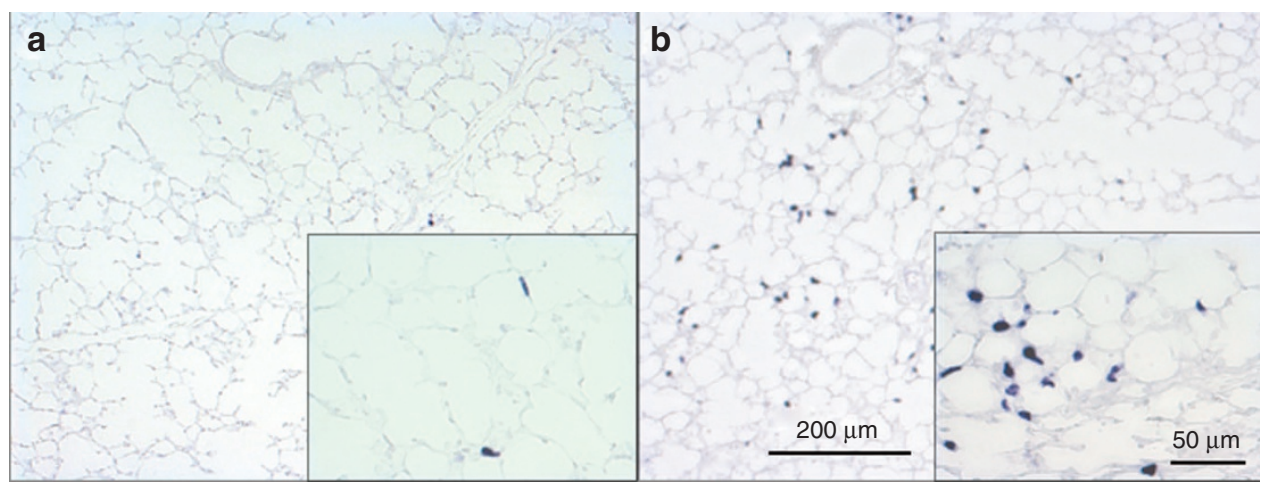

Figure 2. Cellular localization of antimicrobial peptides (AMPs) in preterm fetal sheep lung after intra-amniotic lipopolysaccharide (LPS). Representative photomicrographs of in situ hybridization for cathelin-related peptide. mRNA signal localized to alveolar cells with increased staining at $8 \mathrm{~d}$ after LPS exposure. (a) Control; (b) $8 \mathrm{~d}$ after intra-amniotic LPS (magnification $\times 100$ for main frame and $\times 400$ for insert). 

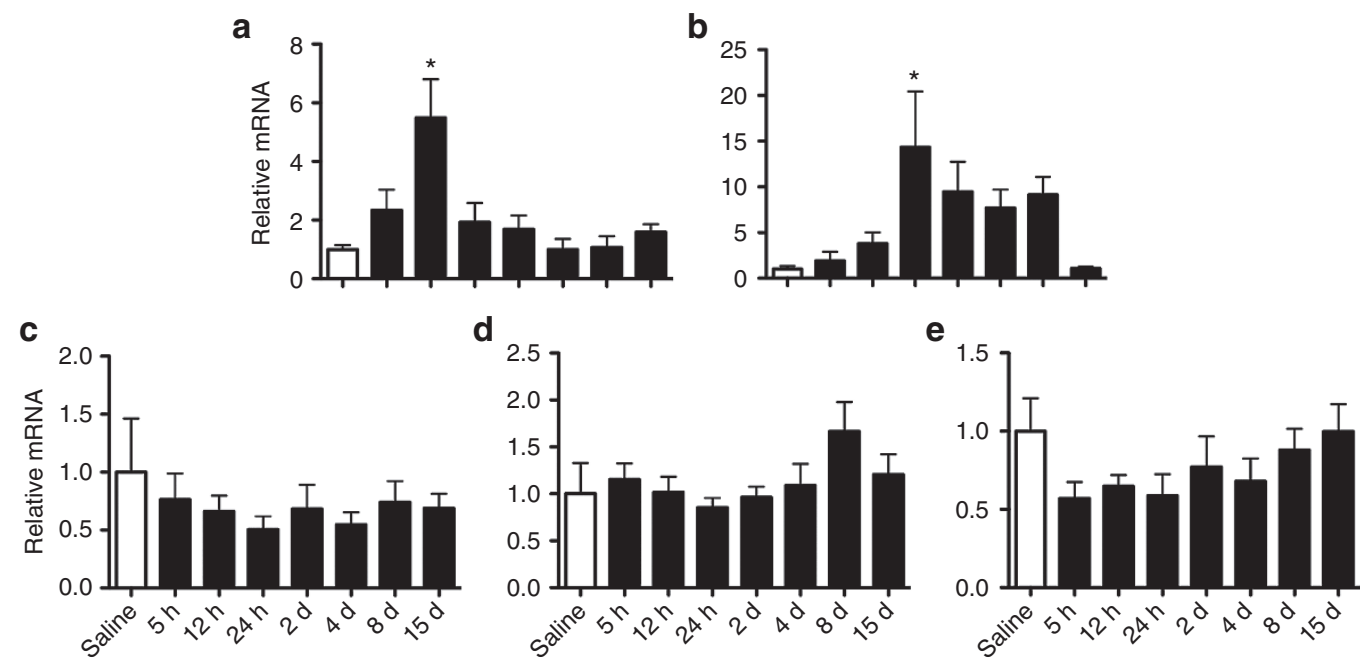

Figure 3. Expression of damage-associated molecular patterns (DAMP) mRNAs in preterm fetal sheep lung after intra-amniotic lipopolysaccharide. Expression of the antimicrobial DAMP mRNAs by reverse-transcriptase quantitative polymerase chain reaction using Taqman probes (Applied Biosystems) was analyzed. (a) IL- $\alpha$ expression peaked at $12 \mathrm{~h}$, (b) lactoferrin peaked at $24 \mathrm{~h}$, (c) high-mobility group box protein-B1 (HMGB1), (d) receptor for advanced glycation endproducts (RAGE), (e) heat-shock protein-70 (HSP70). ( ${ }^{*} P<0.05$ compared to saline).

RAGE, and HSP70 (Figure 4). The bronchial glands and epithelial cells of the bronchi immunostained for lactoferrin (Figure 4a,b). The immunostaining for HMGB1 was diffuse and intense in bronchial epithelial cells, submucosal gland epithelium, alveolar epithelium, and inflammatory cells (Figure $4 \mathrm{c}, \mathbf{d}$ ). The immunostaining for RAGE, the HMGB1 receptor, was also in similar location as HMGB1, although the staining appeared to be less intense (Figure 4e,f). Immunostaining for HSP70 was in occasional airway epithelial cells, and even less frequently in inflammatory and vascular smooth muscle cells. There was an apparent increase in the immunostaining for HSP70 in the airway epithelial cells at $24 \mathrm{~h}$ after LPS exposure (Figure 4g,h).

\section{Proinflammatory Cytokines}

Expression of the proinflammatory cytokines IL-1 $\beta$, tumor necrosis factor (TNF)- $\alpha$, MCP-1, and IL- 8 were increased after LPS exposure (Figure 5). Three temporal patterns of expression were detected. We found IL- 6 had the earliest peak, at $5 \mathrm{~h}$ followed by a subsequent decrease. IL-1 $\beta$, MCP-1, and IL-10 were significantly increased $5-12 \mathrm{~h}$ after exposure, peaking at 2 d. TNF- $\alpha$ and IL-10 were increased only at $2 \mathrm{~d}$.

\section{DISCUSSION}

We report the dynamic expression of AMPs and DAMPs with distinct temporal patterns of expression in the fetal lung following intra-amniotic exposure to LPS. To our knowledge, this is the first study to report the expression AMPs and DAMPs in the preterm fetal lung in response to intrauterine inflammation. The expression of several AMPs decreased $1 \mathrm{~d}$ after exposure to IA LPS. The finding that cathelicidins are subsequently induced in the lung following LPS exposure only after $8 \mathrm{~d}$ is particularly interesting given their role in lung repair. We previously reported that chorioamnionitis induced early lung injury followed by proliferation, consistent with early suppression followed by increased cathelicidin expression detected in this study (17). These results add to our understanding of how antenatal inflammation may be inconsistently associated with bronchopulmonary dysplasia depending on the time of exposure $(4,6)$.

Several $\beta$-defensins have been described in humans, but only two in sheep, which are characteristically expressed in epithelial cells. In humans, $\beta$-defensin 1 is constitutively expressed and not induced (18), while $\beta$-defensin 2 is induced in pulmonary epithelial cells in response to LPS following activation of

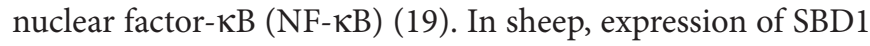
progressively increases in the bronchiolar-alveolar junction from $30 \mathrm{~d}$ prior to term to $15 \mathrm{~d}$ postnatal (13). In normal fetuses and neonatal sheep, $\beta$-defensin 2 is expressed constitutively in small amounts in the lungs (14). SBD1 was upregulated in response to viral infection (20), but suppressed in infection by Gram-negative bacterial (21). Previous studies have shown a large individual variability in the developmental expression of $\beta$-defensins, which we also observed in our samples $(13,14)$. We demonstrate that the intra-amniotic administration of the Gram-negative bacterial cell wall product LPS also suppressed SBD1 and SBD2 early after exposure.

The only known human cathelicidin is LL-37, which is produced by neutrophils, macrophages, and epithelial cells (22). The pulmonary expression of LL-37 can be induced by pulmonary or systemic infection, and LL-37 expression correlates with TNF- $\alpha$ levels (13). Of the several cathelicidins described in sheep, the myeloid antimicrobial peptide 29 (MAP29) was highly effective against common Gram-positive and Gramnegative bacteria (23).

Interestingly, in our study, cathelicidins and defensins were initially suppressed after LPS exposure. Given their antimicrobial role, this suppression could potentially increase fetal susceptibility to further infection from microorganisms. Suppression of the cathelicidin MAP29 was observed 
in pulmonary infection of neonatal lamb with Gram-negative bacteria, in contrast to the previously reported induction following viral infection suggesting differential roles in bacterial or viral infections $(20,21)$.

Both cathelicidins and defensins demonstrate important immunomodulatory function. They can directly recruit leukocytes as well as induce the expression of chemokines. Cathelicidins also inhibit TLR4-mediated release of cytokines in dendritic cells and macrophages as well as release of TNF$\alpha$ from human monocytes $(24,25)$. The complex functions of AMPs suggest an important role in the regulation of the immune response. The early suppression we observed is potentially significant for the fine-tuning of the fetal inflammatory response to chorioamnionitis in the preterm lung.

Besides their role in modulating inflammation AMPs are also important for tissue healing following injury or inflammation. The human $\beta$-defensin 2 stimulates migration and proliferation of endothelial cells to wounds, helping wound closure (26). Specifically in pulmonary cells, neutrophil-derived human defensins enhance proliferation of epithelial cells, accelerating wound closure. This effect is mediated by activation of the epidermal growth factor receptor and its downstream pathway (27). Defensins are also important for cell differentiation during wound healing in the lung. After injury, defensins induce expression of mucins MUC5B and MUC5A in cells of the epithelium (28). The human cathelicidin LL-37 may induce signaling pathways involved in wound closure, activating airway epithelial cells via epidermal growth factor receptor, as well as neovascularization of wounds $(29,30)$. The late induction of the cathelicidins MAP29 and dodecapeptide observed in our study could be involved in the process of tissue healing following inflammation. The in situ hybridization showed that the late upregulation of cathelicidins originated both in epithelial as well as in inflammatory cells, demonstrating the potential role of both these cell types in lung repair. Consistent with our results, the fetal lung exposed to intra-amniotic LPS initially demonstrates injury-increased apoptosis with decreased septation and microvascular injury that recover despite continuous or repeated exposure to LPS $(6,17,31)$.

Regarding the DAMPs, we found that expression of IL- $1 \alpha$ was increased $12 \mathrm{~h}$ after LPS exposure, while IL- $1 \beta$ expression peaked later at $2 \mathrm{~d}$. IL- $1 \alpha$ is expressed constitutively in epithelial and mesenchymal cells and both its precursor and mature forms are active transcription regulators (32). In cell injury induced by hypoxia, IL-1 $\alpha$ is responsible for early recruitment of neutrophils in response to inflammation with little effect on recruitment of macrophages or monocytes, while IL- $1 \beta$ seems to be more important for maintenance of the inflammatory response and recruitment of macrophages (33). Our findings are consistent with the role described for early recruitment of inflammatory cells. Potentially, IL- $1 \alpha$ has a similar role in the fetal inflammatory response being an early mediator of chemotaxis followed by later expression of IL- $1 \beta$.

The expression of another DAMP, lactoferrin was increased at $24 \mathrm{~h}$. Epithelial cells and neutrophils can produce lactoferrin, and we observed it localized to the bronchial glands. Lactoferrin

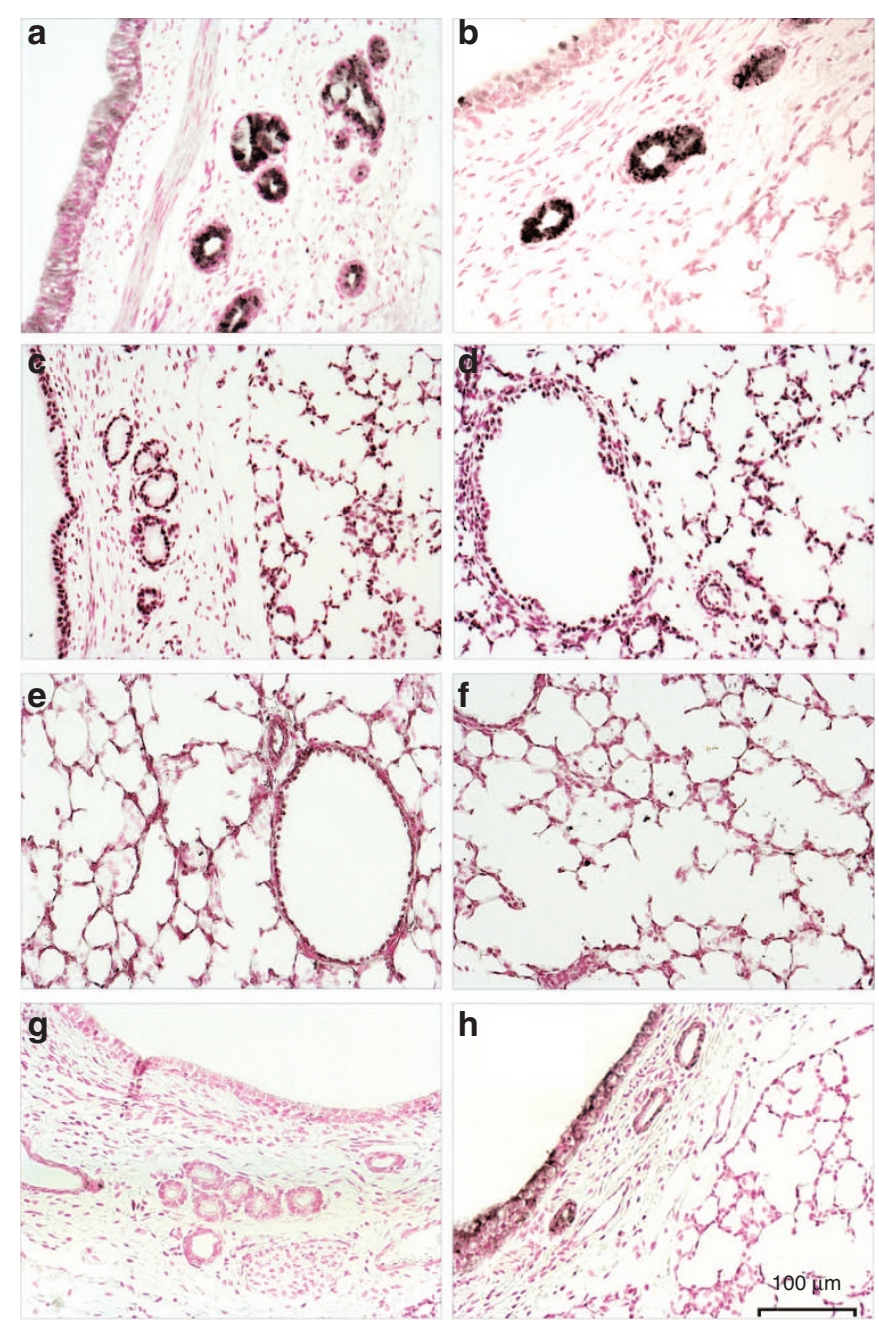

Figure 4. Cellular localization of damage-associated molecular patterns (DAMPs) in preterm fetal sheep lung after intra-amniotic lipopolysaccharide (LPS). Representative photomicrographs showing immunostaining for the following: lactoferrin depicting staining of bronchial glands and bronchial epithelial cells in control (a) and $24 \mathrm{~h}$ after LPS exposure (b), high-mobility group box protein-B1 (HMGB1) with diffuse and strong nuclear staining of alveolar cells in control (c) and $24 \mathrm{~h}$ after LPS exposure (d); receptor for advanced glycation endproducts (RAGE) showed weaker staining of alveolar cells in control (e) and strong staining of inflammatory cells $24 \mathrm{~h}$ after LPS exposure (f); heat-shock protein-70 (HSP70) showing immunostaining in the epithelial airway cells in the control group (g), with increased staining at $24 \mathrm{~h}$ after LPS exposure (h).

has antimicrobial properties by both chelating iron and disrupting bacterial cell membrane (34). Lactoferrin has the ability to bind LPS preventing further activation of the inflammatory response and production of proinflammatory cytokines (35). The increased expression of lactoferrin in response to chorioamnionitis has the potential to increase the innate ability to kill invading microorganisms while limiting local inflammatory response and damage. The staining pattern observed was consistent with what has been reported in the literature, however, no difference was observed in the immunostaining, which could be due to the rapid secretion of the peptide from the bronchial glands.

Even though there was no difference in the mRNA level for HSP70, we observed increased immunostaining at 12 and $24 \mathrm{~h}$ 
a

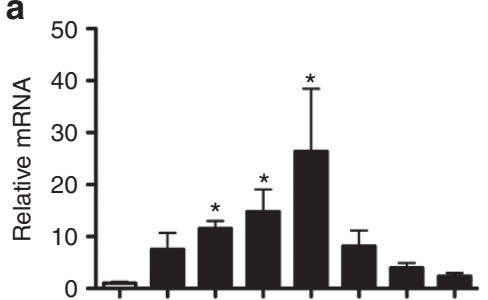

d

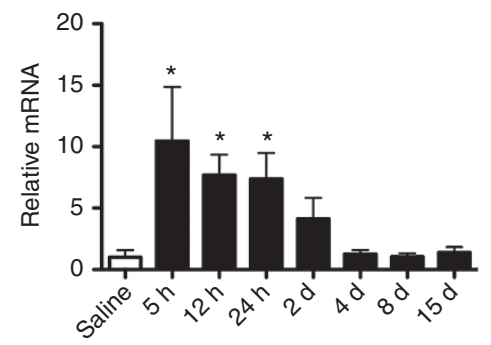

b

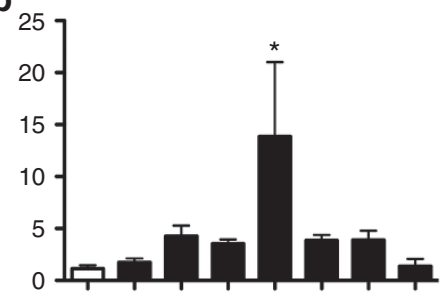

e

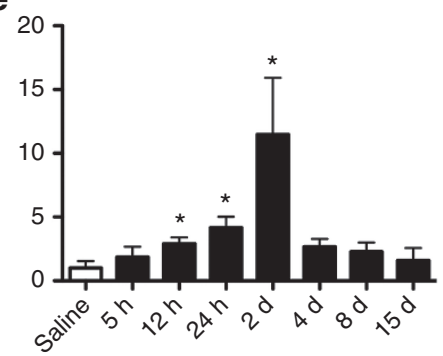

C

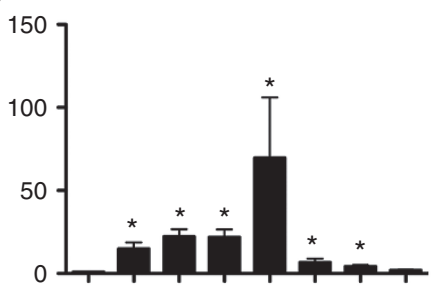

f

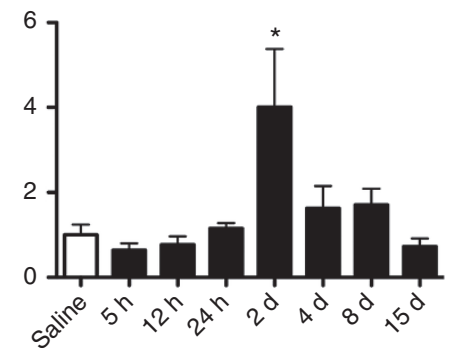

Figure 5. Different temporal patterns of expression of proinflammatory cytokines/chemokines in preterm fetal sheep lung after intra-amniotic lipopolysaccharide. mRNA expression of the cytokines/chemokines by reverse-transcriptase quantitative polymerase chain reaction using Taqman probes was analyzed. (a) IL-1 $\beta$, (b) TNF- $\alpha$, (c) MCP-1, (d) IL-6, (e) IL-8, (f) IL-10. Different temporal patterns of expression were noted with early expression for IL-6 and MCP-1 and later expression for TNF- $\alpha$ and IL-10. The expression for IL-1 $\beta$, IL-8, and MCP-1 started 5-12 $\mathrm{h}$ after intra-amniotic lipopolysaccharide with a peak at 2 d. ${ }^{*} P<0.05$ compared to saline.

after LPS exposure. This difference was seen only in the airway epithelium and the conflicting results might be related to the localization of HSP70 as we observed previously with a volutrauma injury (36). Besides, the discrepancy between immunostaining and the mRNA quantitation could be due to post-transcriptional regulations, since the mRNA for HSP70 has been shown to be subject to microRNA regulation leading to supression of translation and polyadenylation leading the increased translation. HSP70 appears to have cytoprotective role in the lung epithelium against LPS and hypoxia-mediated injury (37). Expression of HMGB1 and its receptor RAGE in the lung were not affected by LPS exposure.

Among the proinflammatory cytokines IL-6 and MCP-1 had the earliest increase in expression at $5 \mathrm{~h}$ after LPS exposure, while the remainder cytokines peaked at $2 \mathrm{~d}$. This response pattern suggests a role of IL- 6 and MCP- 1 in the initiation of pulmonary inflammation in chorioamnionitis. We previously reported that MCP-1 is expressed in the lung mesenchymal cells potentially suggesting a role for these lung cells in the initiation of lung inflammation (38). In contrast to the early induction of IL- 6 and MCP-1, TNF- $\alpha$, and IL-10 mRNAs were only increased at $2 \mathrm{~d}$, suggesting that these cytokines play a secondary role in modulating the lung inflammation after LPS induced chorioamnionitis.

We present a novel report of the time course expression of pro- and anti-inflammatory cytokines in a model of chorioamnionitis. Our study provides insight on the expression of AMPs and DAMPs in the early and late pulmonary responses to intrauterine inflammation. The early suppression of both cathelicidins and defensins could potentially increase fetal susceptibility to further infection. The late induction of cathelicidins MAP29 and dodecapeptide could be related to their role in tissue repair following inflammatory injury.

\section{METHODS}

\section{Animals}

The Animal Care and Use Committees of the Cincinnati Children's Hospital Medical Center and University of Western Australia approved the study protocol. All procedures involving animals were performed at The University of Western Australia (Perth, Australia). Time-mated Merino ewes with singleton fetuses were randomly assigned to groups for exposure to either $10 \mathrm{mg}$ of intra-amniotic LPS from Escherichia coli (Sigma Aldrich, St Louis, MO) diluted in $2 \mathrm{ml}$ of sterile saline or $2 \mathrm{ml}$ of sterile saline as control. This dose of LPS has been shown to induce chorioamnionitis and fetal inflammatory response (39). The inflammatory response of the fetal thymus was reported previously for this series of animals (16).

Intra-amniotic LPS or saline was dosed at one of the following time points: $5 \mathrm{~h}, 12 \mathrm{~h}, 24 \mathrm{~h}, 2 \mathrm{~d}, 4 \mathrm{~d}, 8 \mathrm{~d}$, or $15 \mathrm{~d}$ with ultrasound guidance (39) prior to preterm delivery at $125 \pm 2 \mathrm{~d}$. We used five to seven animals per group. Ewes were euthanized with $100 \mathrm{mg} / \mathrm{kg}$ of intravenous pentobarbital with rapid surgical delivery of the fetus (16). Fetal lungs for mRNA analysis were quickly dissected and snap frozen. For histological analysis, the right upper lobe of the lung was inflated fixed with $10 \%$ buffered formalin at a pressure of $30 \mathrm{cmH}_{2} \mathrm{O}$, and further processed to embed in paraffin (40).

\section{Relative mRNA Quantitation}

Total RNA was isolated from frozen lungs after homogenization with TRIzol (Invitrogen, Carlsbad, CA) as previously described (40). Reverse transcription was performed using Verso cDNA kit (Thermo Scientific, Waltham, MA) to produce single-strand cDNA. The genes IL-1 $\beta$, TNF- $\alpha$, MCP-1, Il-6, IL-8, IL-10, IL-1 $\alpha$, SBD1, SBD2, MAP29, dodecapeptide, lactoferrin, HMGB1, RAGE, and HSP70 were amplified using the cDNA template and sheep-specific primers along with Taqman probes (Applied Biosystems, Foster City, CA). The mRNA expression for each gene was normalized to the mRNA for the ribosomal protein $18 \mathrm{~s}$ as internal standard. Final data were expressed as fold increase over the control value.

\section{Immunohistochemistry}

Sections from formalin-fixed tissues in paraffin blocks were deparaffinized and rehydrated before microwave-assisted antigen retrieval in citric acid buffer at $\mathrm{pH}$ 6.0. Endogenous peroxidase activity was blocked with $\mathrm{CH}_{3} \mathrm{OH} / \mathrm{H}_{2} \mathrm{O}_{2}$ treatment and were blocked with $2 \%$ bovine serum albumin in phosphate-buffered saline. Sections were 
incubated overnight at $4{ }^{\circ} \mathrm{C}$ with the primary antibody diluted in $2 \%$ serum in phosphate-buffered saline (7). We used the following primary antibodies: lactoferrin (Abcam, Cambridge, MA, dilution 1:50), HMGB1 (R\&D Systems, Minneapolis, MN, dilution 1:50), RAGE (AbD Serotec, Oxford, UK, dilution 1:1,000), HSP70 (Biogenex, San Ramon, CA, dilution 1:50). Sections were then washed and incubated with the appropriate species-specific secondary antibody diluted $1: 200$ in $2 \%$ serum for $2 \mathrm{~h}$ at room temperature. After further washing, antigen:antibody complexes were visualized using a Vectastain ABC peroxidase kit (Vector Laboratories, Burlingame, CA). Antigen detection was enhanced with nickel-diaminobenzidine, followed by incubation with TRIS-cobalt. Slides were counterstained with Nuclear Fast Red for photomicroscopy.

\section{In Situ Hybridization}

In situ localization of mRNA was performed with digoxigenin-labeled anti-sense sheep riboprobes for cathelin-related peptide that crossreacts with all sheep cathelicidins (forward: TGT GGC TCC TGC TGC TGG GAT TA; reverse: TAT GAT GCG ACA TAT TCG GGC TGC). Digoxigenin-labeled riboprobes (sense and anti-sense) were synthesized from cDNA templates using DIG RNA labeling kits (Roche Diagnostics, Mannheim, Germany) and diluted in hybridization buffer to a final concentration of $1 \mu \mathrm{g} / \mathrm{ml}$. The sections were pretreated with $4 \%$ paraformaldehyde, treated with proteinase $\mathrm{K}$, and hybridized with the probe overnight at $61^{\circ} \mathrm{C}$, based on GC content. Sections were washed with formamide, treated with RNase A $(100 \mu \mathrm{g} / \mathrm{ml})$, and then blocked with $10 \%$ horse serum. Following incubation overnight at $4{ }^{\circ} \mathrm{C}$ with anti-digoxigenin antibody (Roche Diagnostics), the slides were developed with nitro blue tetrazolium-5-bromo-4-chloro-3-indolyl phosphate (Roche Diagnostics) in the absence of ambient light using dark boxes. The slides were monitored for color development, and then stopped with Tris-ethylene-diamine-tetraacetic acid buffer. Controls for specificity of ribo-probe binding were done with the use of the homologous (sense) probe.

\section{Statistical Analysis}

Values are expressed and depicted in graphs as means \pm SD. All analysis were performed using the software GraphPad Prism version 5.00 for Windows (GraphPad Software, San Diego, CA). mRNA expression levels were compared using one-way ANOVA and each group was individually compared to the control group using t-test. Values of $P<0.05$ were considered significant.

\section{STATEMENT OF FINANCIAL SUPPORT}

This work was supported by US National Institute of Child Health and Human Development Grant HD-57869 (S.G.K.).

Disclosure: The authors have no financial disclosures or conflict of interest.

\section{REFERENCES}

1. Kemp MW, Kannan PS, Saito M, et al. Selective exposure of the fetal lung and skin/amnion (but not gastro-intestinal tract) to LPS elicits acute systemic inflammation in fetal sheep. PLoS One 2013;8:e63355.

2. Lahra MM, Beeby PJ, Jeffery HE. Intrauterine inflammation, neonatal sepsis, and chronic lung disease: a 13-year hospital cohort study. Pediatrics 2009;123:1314-9.

3. Viscardi RM, Muhumuza CK, Rodriguez A, et al. Inflammatory markers in intrauterine and fetal blood and cerebrospinal fluid compartments are associated with adverse pulmonary and neurologic outcomes in preterm infants. Pediatr Res 2004;55:1009-17.

4. Hartling L, Liang Y, Lacaze-Masmonteil T. Chorioamnionitis as a risk factor for bronchopulmonary dysplasia: a systematic review and meta-analysis. Arch Dis Child Fetal Neonatal Ed 2012;97:F8-F17.

5. Willet KE, Kramer BW, Kallapur SG, et al. Intra-amniotic injection of IL-1 induces inflammation and maturation in fetal sheep lung. Am J Physiol Lung Cell Mol Physiol 2002;282:L411-20.

6. Kallapur SG, Nitsos I, Moss TJ, et al. Chronic endotoxin exposure does not cause sustained structural abnormalities in the fetal sheep lungs. Am J Physiol Lung Cell Mol Physiol 2005;288:L966-74.
7. Kallapur SG, Nitsos I, Moss TJ, et al. IL-1 mediates pulmonary and systemic inflammatory responses to chorioamnionitis induced by lipopolysaccharide. Am J Respir Crit Care Med 2009;179:955-61.

8. Takeuchi O, Akira S. Pattern recognition receptors and inflammation. Cell 2010;140:805-20.

9. Hillman NH, Moss TJ, Nitsos I, et al. Toll-like receptors and agonist responses in the developing fetal sheep lung. Pediatr Res 2008;63: 388-93.

10. Chen GY, Nuñez G. Sterile inflammation: sensing and reacting to damage. Nat Rev Immunol 2010;10:826-37.

11. Lai Y, Gallo RL. AMPed up immunity: how antimicrobial peptides have multiple roles in immune defense. Trends Immunol 2009;30:131-41.

12. Doss M, White MR, Tecle T, Hartshorn KL. Human defensins and LL-37 in mucosal immunity. J Leukoc Biol 2010;87:79-92.

13. Meyerholz DK, Kawashima K, Gallup JM, Grubor B, Ackermann MR. Expression of select immune genes (surfactant proteins A and D, sheep beta defensin 1, and toll-like receptor 4 ) by respiratory epithelia is developmentally regulated in the preterm neonatal lamb. Dev Comp Immunol 2006;30:1060-9.

14. Meyerholz DK, Gallup JM, Grubor BM, et al. Developmental expression and distribution of sheep beta-defensin-2. Dev Comp Immunol 2004;28:171-8.

15. Ménard S, Förster V, Lotz M, et al. Developmental switch of intestinal antimicrobial peptide expression. J Exp Med 2008;205:183-93.

16. Kuypers E, Wolfs TG, Collins JJ, et al. Intraamniotic lipopolysaccharide exposure changes cell populations and structure of the ovine fetal thymus. Reprod Sci 2013;20:946-56.

17. Kramer BW, Kramer S, Ikegami M, Jobe AH. Injury, inflammation, and remodeling in fetal sheep lung after intra-amniotic endotoxin. Am J Physiol Lung Cell Mol Physiol 2002;283:L452-9.

18. Singh PK, Jia HP, Wiles K, et al. Production of beta-defensins by human airway epithelia. Proc Natl Acad Sci USA 1998;95:14961-6.

19. Diamond G, Kaiser V, Rhodes J, Russell JP, Bevins CL. Transcriptional regulation of beta-defensin gene expression in tracheal epithelial cells. Infect Immun 2000;68:113-9.

20. Grubor B, Gallup JM, Meyerholz DK, et al. Enhanced surfactant protein and defensin mRNA levels and reduced viral replication during parainfluenza virus type 3 pneumonia in neonatal lambs. Clin Diagn Lab Immunol 2004;11:599-607.

21. Ackermann MR, Gallup JM, Zabner J, et al. Differential expression of sheep beta-defensin- 1 and -2 and interleukin 8 during acute Mannheimia haemolytica pneumonia. Microb Pathog 2004;37:21-7.

22. Tjabringa GS, Rabe KF, Hiemstra PS. The human cathelicidin LL-37: a multifunctional peptide involved in infection and inflammation in the lung. Pulm Pharmacol Ther 2005;18:321-7.

23. Travis SM, Anderson NN, Forsyth WR, et al. Bactericidal activity of mammalian cathelicidin-derived peptides. Infect Immun 2000;68:2748-55.

24. Morioka Y, Yamasaki K, Leung D, Gallo RL. Cathelicidin antimicrobial peptides inhibit hyaluronan-induced cytokine release and modulate chronic allergic dermatitis. J Immunol 2008;181:3915-22.

25. Mookherjee N, Brown KL, Bowdish DM, et al. Modulation of the TLRmediated inflammatory response by the endogenous human host defense peptide LL-37. J Immunol 2006;176:2455-64.

26. Baroni A, Donnarumma G, Paoletti I, et al. Antimicrobial human betadefensin-2 stimulates migration, proliferation and tube formation of human umbilical vein endothelial cells. Peptides 2009;30:267-72.

27. Aarbiou J, Ertmann M, van Wetering S, et al. Human neutrophil defensins induce lung epithelial cell proliferation in vitro. J Leukoc Biol 2002;72:16774.

28. van Wetering S, Tjabringa GS, Hiemstra PS. Interactions between neutrophil-derived antimicrobial peptides and airway epithelial cells. J Leukoc Biol 2005;77:444-50.

29. Koczulla R, von Degenfeld G, Kupatt C, et al. An angiogenic role for the human peptide antibiotic LL-37/hCAP-18. J Clin Invest 2003;111:1665-72. 
30. Tjabringa GS, Aarbiou J, Ninaber DK, et al. The antimicrobial peptide LL-37 activates innate immunity at the airway epithelial surface by transactivation of the epidermal growth factor receptor. J Immunol 2003;171:6690-6.

31. Kallapur SG, Bachurski CJ, Le Cras TD, Joshi SN, Ikegami M, Jobe AH. Vascular changes after intra-amniotic endotoxin in preterm lamb lungs. Am J Physiol Lung Cell Mol Physiol 2004;287:L1178-85.

32. Dinarello CA. Interleukin-1 in the pathogenesis and treatment of inflammatory diseases. Blood 2011;117:3720-32.

33. Rider P, Carmi Y, Guttman O, et al. IL- $1 \alpha$ and IL- $1 \beta$ recruit different myeloid cells and promote different stages of sterile inflammation. J Immunol 2011;187:4835-43.

34. Singh PK, Parsek MR, Greenberg EP, Welsh MJ. A component of innate immunity prevents bacterial biofilm development. Nature 2002;417:552-5.

35. Kruzel ML, Harari Y, Mailman D, Actor JK, Zimecki M. Differential effects of prophylactic, concurrent and therapeutic lactoferrin treatment on LPS-induced inflammatory responses in mice. Clin Exp Immunol 2002;130:25-31.

36. Hillman NH, Kallapur SG, Pillow JJ, et al. Airway injury from initiating ventilation in preterm sheep. Pediatr Res 2010;67:60-5.

37. Wheeler DS, Wong HR. Heat shock response and acute lung injury. Free Radic Biol Med 2007;42:1-14.

38. Shah TA, Hillman NH, Nitsos I, et al. Pulmonary and systemic expression of monocyte chemotactic proteins in preterm sheep fetuses exposed to lipopolysaccharide-induced chorioamnionitis. Pediatr Res 2010;68:210-5.

39. Kallapur SG, Willet KE, Jobe AH, Ikegami M, Bachurski CJ. Intra-amniotic endotoxin: chorioamnionitis precedes lung maturation in preterm lambs. Am J Physiol Lung Cell Mol Physiol 2001;280:L527-36.

40. Kallapur SG, Kramer BW, Nitsos I, et al. Pulmonary and systemic inflammatory responses to intra-amniotic IL-1 $\alpha$ in fetal sheep. Am J Physiol Lung Cell Mol Physiol 2011;301:L285-95. 